\title{
Kemijska veza u hrvatskim udžbenicima
}

\author{
N. Raos* \\ Institut za medicinska istraživanja i medicinu rada \\ Ksaverska c. 2, p.p. 291 \\ 10001 Zagreb
}

\section{|| Sažetak}

Analiza sadržaja hrvatskih kemijskih školskih knjiga u 20. stoljeću pokazuje da se elektrolitička disocijacija počela učiti 1912. godine, no kemijska veza, kao pojava koja proizlazi iz strukture atoma, pojavljuje se u sveučilišnom i srednjoškolskom udžbeniku tek 1947., 31 godinu nakon Lewisovih formula (1916.) i 21 godinu nakon Schrödingerove jednadžbe (1926.). Na uvođenje Lewisovih formula najvjerojatnije je utjecao Paulingov udžbenik "The Nature of the Chemical Bond" (1939.), a u kašnjenju našeg školskog programa za znanstvenim otkrićima ulogu su odigrale i ratne prilike (1941. - 1945.).

\| Ključne riječi

Povijest kemije, nastava kemije, strukturne formule, konstitucija molekula

\section{Uvod}

Konstitucija kao temeljno strukturno obilježje molekule može se dvojako razumjeti. ${ }^{1-4}$ Ona može proizlaziti iz čisto empirijskih svojstava čiste tvari, točnije rečeno konstitucija se, a ne samo kompozicija, može izvesti iz stehiometrije. Atom nekog elementa može se, naime, spojiti s određenim brojem atoma vodika, iz čega proizlazi njegova "atomičnost", što je najstariji naziv za valentnost. Riječ je dakle o čisto kemijskoj strukturi molekule: crtež povezanih atoma samo je osebujna shema mogućih kemijskih reakcija (npr. $\mathrm{C}-\mathrm{OH}$ ukazuje na mogućnost oksidacije $\mathrm{u}-\mathrm{CHO}$ i - $\mathrm{COOH}$ ). Prvu takvu, "kemijsku" strukturu nalazimo već u Daltonovim formulama iz 1808. godine, ${ }^{5}$ no ona dobiva pravi smisao tek 1860. kada je u Karlsruheu održan prvi međunarodni skup kemičara. ${ }^{6} \mathrm{Na}$ tom je kongresu naime jasno utvrđena razlika između atomske i ekvivalentne težine te atoma i molekule, čime je čvrsto definirano značenje molekulske formule. ${ }^{* *}$ Najveći zagovornik takve, kemijske interpretacije molekulske strukture bio je ruski kemičar Aleksandr Mihailovič Butlerov (1826. - 1886.). ${ }^{7-9}$

Druga, "fizička" interpretacija kemijske strukture postala je moguća tek nakon što su atomi i molekule prestale biti hipotetičke čestice. ${ }^{10-13}$ Teško bi bilo izdvojiti događaj koji je to toga doveo; najbolje bi bilo reći da istraživanje strukture atoma i molekula započinje Arrheniusovom teorijom elektrolitičke disocijacije (1887.), otkrićem elektrona (J. J. Thompson, 1897.), Einsteinovim (1905.) i Perrinovim (1909.) dokazima o stvarnom postojanju molekula da bi

\footnotetext{
*Dr. sc. Nenad Raos

e-pošta: raos@imi.hr

** I vrste formula povijesno su uvjetovane. Nekoć se jasno razlikovala molekularna od empirijske formule. Molekularna formula govori o sastavu molekule, dok empirijska daje samo podatak o njezinom elementarnom sastavu: molekularna formula glukoze je $\mathrm{C}_{6} \mathrm{H}_{12} \mathrm{O}_{6}$, a empirijska $\mathrm{CH}_{2} \mathrm{O}$.
}

pun zamah dobilo nakon Rutherfordova otkrića atomske jezgre (1911.) i Moseleyeva mjerenja njezina naboja (protonskog broja) iz spektra rendgenskog zračenja (1913.). Ta su istraživanja na kraju dovela do Bohrova modela atoma (1913.) i Schrödingerove jednadžbe (1926.) te - što je sa stajališta ovog članka najvažnije - do Lewisovih strukturnih formula (1916.). ${ }^{14,15}$

Istom s Gilbertom Newtonom Lewisom (1875. - 1946.) konstitucija molekula dobiva pravi fizički smisao: kemijska veza posljedica je elektronske strukture atoma, bez obzira nastaje li seljenjem (ionska veza), dijeljenjem (kovalentna veza) ili doniranjem elektrona (koordinativna veza). Sve se kemijske veze, prema Lewisu, temelje na pravilu okteta, tj. zahtjevu da atom mora posve ispuniti svoju posljednju, valencijsku ljusku. To pravilo ima, dakako, i iznimaka, da ne govorimo o tome kako je kemijska veza mnogo složenija pojava nego što se može prikazati jednostavnim, posve kvalitativnim Lewisovim modelom. Ipak, Lewisove "točkice i crtice" zaživjele su u udžbenicima, pružajući učenicima i studentima racionalnu osnovu za pisanje konstitucijskih formula.

Namjera ovog članka nije, razumije se, ulaženje u finese predodžbi kemijske veze, nego je prije svega pokušaj odgovora na pitanje kako školske knjige prenose nove znanstvene spoznaje. Radi toga pregledao sam veći broj osnovnoškolskih, srednjoškolskih i sveučilišnih udžbenika koji su unazad stotinu godina izišli u Hrvatskoj. U tom kontekstu treba reći kako je Lewis do kraja razvio teoriju kemijske veze 1923. godine ${ }^{16}$ (uz gotovo jednako važan doprinos Irvinga Langmuira (1881. - 1957.), ${ }^{17}$ a da je njezinu širenju (uz mnoge druge nove predodžbe) vrlo pridonio Linus Pauling (1901. - 1994.) svjetski poznatim udžbenikom The Nature of the Chemical Bond iz 1939, ${ }^{18}$ koji je doživio još dva dopunjena izdanja (1940. i 1960. godine). 


\section{Ioni i kemijske veze}

Teorija elektrolitičke disocijacije uči se u hrvatskih srednjim školama od početka prošlog stoljeća; nalazimo je potpuno objašnjenu već u Šandorovu udžbeniku iz 1912. godine ("Rastope li se elektroliti u vodi, razilazit će se neki dio molekula (disocira) na ione"), nakon čega slijede primjeri elektrolitičke disocijacije natrijeva klorida, bakrova(II) sulfata, kalijeva hidroksida i sumporne kiseline $\left(\mathrm{H}_{2} \mathrm{SO}_{4}=\mathrm{H} \cdot+\mathrm{H} \cdot+\mathrm{SO}_{4}{ }^{\prime \prime}\right) \cdot{ }^{19}$ Naša se pak šira kulturna javnost prvi put upoznala s tom teorijom 1929. kada je izišla znanstveno-popularna knjiga Frana Bubanovića (1883. - 1955.) ${ }^{20}$ "Iz moderne kemije", ${ }^{21}$ kao nastavak i dopuna "Slika iz kemije"22 iz 1917. godine. U njoj je Bubanović posvetio čitavo poglavlje Svanteu Arrheinusu (1859. - 1927.), utemeljitelju teorije. Arrheniusa je Bubanović osobno poznavao, jer je kod njega studirao, a poslije se s njime i zbližio. ${ }^{23,24}$ Možda će baš zbog toga čitatelj u knjizi uzalud tražiti tumačenje suvremene teorije kemijske (ionske) veze, jer o tome Bubanović (str. 117/8) kaže samo ovo:

Ukratko i jednostavno kazano, sudioništvo je Arrheniusovo u izgradnji moderne nauke o otopinama u tome, što je on osobito naglasio važnost elektricitetom nabijenih čestica u vodenim otopinama, što ih je već veliki Faraday nazvao iontima (putnicima). A Arrhenius je uočio značenje njihovo kao najaktivnijih sastavnih dijelova otopina, ne samo u pogledu električne vodljivosti, nego i u pogledu ostalih fizikalnih, kemijskih, fizioloških $i t$. d. svojstava vodene otopine. On je ujedno razvio metode, s pomoću kojih se može aktivnost t. zv. slobodnih ionata u nekoj otopini brojčano fiksirati.

U sveučilišnom udžbeniku, koji je izišao nedugo nakon rečene znanstvenopopularne knjige, ${ }^{25}$ Bubanović se naveliko bavi teorijom elektrolitskih otopina, a posebice ravnotežom u njima, no ne smatra ionsku vezu posebnom vrsti kemijske veze, pa stoga primjerice kalcijev hipoklorit piše kao $\mathrm{Cl} \cdot \mathrm{O}-\mathrm{Ca}-\mathrm{O} \cdot \mathrm{Cl}$ (str. 290). Još se više ionima i ionskim ravnotežama Bubanović pozabavio u drugom izdanju Kemije. ${ }^{26} \mathrm{U}$ njoj nalazimo vrlo dobro prikazanu fizikalnu kemiju elektrolitičkih otopina, što ne treba čuditi ne samo zbog Bubanovićeva profesionalnog usmjerenja nego i zbog važnosti osmotskih pojava u medicini, a posebice u fiziologiji.

\section{Lewisove strukture i kovalentna veza}

Unatoč davanju težine elektrolitičkoj disocijaciji i ionskim ravnotežama, u prvom izdanju Bubanovićeve Kemije nema ni traga govoru o suvremenoj (Lewisovoj) teoriji kovalentne veze: crtice koje povezuju atome tek su izraz empirijski određene valentnosti (slika 1). O vezi strukture atoma s kemijskom vezom govori tek jednom rečenicom ("Kod toga držimo, da ti spoljašnji elektroni, nose odgovornost za kemijski karakter, dakle za afinitet i valenciju nekoga elementarnoga atoma", str. 328), ${ }^{25}$ a u udžbeniku organske kemije (str. 3) o valentnosti ugljika kaže samo ovo: "Budući da ugljik zauzima centralno mjesto u svom nizu - a to je drugi niz periodskog sistema - to mi sebi zamišljamo, da se vanredna podatljivost i kemijska aktivnost ugljikova atoma svodi na to, što se taj atom po svojoj strukturi nalazi u osobito labilnu stanju i zato da živo nastoji da postigne stabil- nost, pa poradi toga gubi dotično prima izvjesne elektrone u spoljašnji svoj krug." ${ }^{27}$ Slično tumačenje kemijske veze nalazimo i u srednjoškolskim knjigama. Pinterović tako piše 1940. godine u poglavlju "Građa atoma" (str. 157): "Iz tabele vidimo u kakvoj su vezi prirodni sistem elemenata i elektronske ljuske. Elementi s jednim elektronom u vanjskoj ljusci su jednovalentni ( $\mathrm{Li}, \mathrm{Na}, \mathrm{K})$, s dva elektrona dvovalentni (Be, Mg, Ca) i t. d. " , ${ }^{28}$ dok u drugom, ratnom izdanju knjige i takvo tumačenje izostaje iako je tekst o strukturi atoma, pa čak i slika kristalne rešetke natrijeva klorida (ali bez iona!), ostao nepromijenjen. ${ }^{29}$

Velika većina elemenata nema uvijek jednu te istu valjanost, ali ih ima, kao na pr. kisik, koji gotovo u svim svojim spojevima zadržavaju istu valenciju. Elementi, koji imadu više valencija, obično su u spojevima s vodikom u nižoj valenciji, dok u spojevima s kisikom mogu dotjerati i do najviše svoje valencije. Valjanost pojedinih elemenata kod pisanja elemenata i kemijskih spojeva spomoću simbola i formula označujeino zgodnim pomagalima. Tako na pr. pišemo:

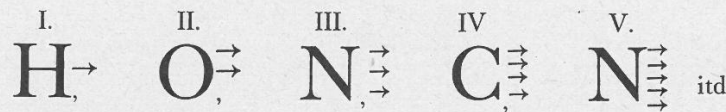

Zatim spojeve

$\mathrm{H}-\mathrm{Cl}$, klorovodik, $\mathrm{H}-\mathrm{O}-\mathrm{H}$ voda, $\mathrm{N}=\frac{\mathrm{H}}{\mathrm{H}}$ amonijak, VI. $\mathrm{C} \equiv \mathrm{O}=\mathrm{CO}_{2}$, ugljični dvokis, $\mathrm{S} \equiv \mathrm{O}=\mathrm{O}=\mathrm{SO}_{3}$ sumporni trokis; $\mathrm{H}_{2} \mathrm{SO}$ sumporna kiselina, koja ima prema valenciii svojih elementarnih

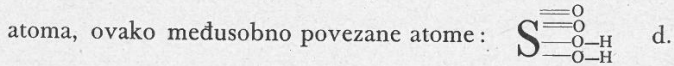

Iz svega ovoga razbiramo, da je vodikov atom uvijek jednovaljan, pa je zato on jedinica za valenciju. Koliko su pojedini drugi elementi valjani razbraćemo najbrže iz pregledne tabele elemenata, koja se zove prirodni periodski sistem elemenata. Ta se tabela nalazi u našoj knjizi i obično na zidu svakog kemijskog laboratorija. Što ona znači, upoznaćemo naskoro!

Slika 1 - Kemijska teorija valencije iz prvog izdanja Bubanovićeve Kemije (ref. 25, str. 128): "Iz svega toga razabiremo, da je vodikov atom uvijek jednovalentan, pa je on jedinica za valenciju".

Fig. 1 - The chemical theory of valence from the first edition of Bubanović chemistry textbook (Ref. 25, p. 128): "From this it can be concluded that the hydrogen atom is in every case univalent, and thus it is the unit of valence."

Do preokreta dolazi poslije završetka Drugoga svjetskog rata, ali ne odmah. U Bubanovićevu "Praktikumu medicinske kemije" iz 1946. ne nalazimo još ni spomena teorije kemijske veze, ${ }^{30}$ dok se Ferić nalazi ponukanim da se u uvodu udžbenika za farmaceute (str. 5) za to ispriča studentima: "Nije mi nažalost bilo moguće ovdje dati i prikaz prirodnog sistema elemenata, teorije atoma, elektrokemijske teorije valencije te nešto o kompleksnim spojevima, što bi, držim, svakako spadalo u okvir ovog 'Uvoda'. Nadam se međutim, da će mi se za to pružiti prilika." ${ }^{\prime 31}$

Godine 1947. izlazi drugo izdanje Kemije, knjige u kojoj Bubanović čitavih 18 stranica (str. 292 - 309) posvećuje suvremenoj, elektronskoj teoriji kemijske veze ("7. Značenje moderne teorije o strukturi materije za objašnjenje kemijskog zbivanja"). ${ }^{26} \mathrm{U}$ tom dijelu knjige možemo čitati o "he- 
teropolarnom ili ionskom vezivanju", koje se još zove "ionska valencija", potom o kovalentnim vezama ("atomsko vezivanje", "atomske valencije"), "metalnim ili kovinskim valencijama", pa i o "koordinativnim valencijama" (u kompleksnim spojevima). $U$ istoj godini izlazi i prva srednjoškolska knjiga sa suvremenim (elektronskim) formulama, no tu je riječ o prijevodu ruskog udžbenika (slika 2). U njoj autor, profesor Hercenova pedagoškog instituta, spominje (str. 56), za razliku od Bubanovića, i povijest novih formula ("Suvremene predodžbe o strukturi molekula osnivaju se na hipotezi, koju su istodobno objavili njemački učenjak Kossel i američki učenjak Lewis"). ${ }^{32}$

\section{(Ne)suvremenost udžbenika}

Unatoč činjenici da se u srednjoškolskom udžbeniku pojam iona, i s njim povezana elektrolitička disocijacija po-

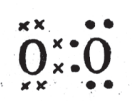

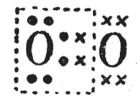

S1. 181. i 182. Molekula kisika

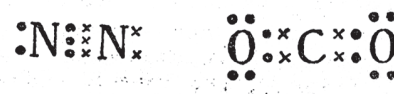

S1. 183. Molekule dušika uglijičnog dioksida
Slika 2 - Godine 1947. pojavile su se prve Lewisove formule u hrvatskom gimnazijskom udžbeniku (ref. 32, str. 67) no on je preveden s ruskog.

Fig. 2 - In 1947 the first Lewis formulas were published in the Croatian textbook for high schools (Ref. 32, p. 67) - but it was the book translated from Russian.

javljuje već 1912., a potpuna (Lewisova) teorija valencije 1947. godine, iz tablice 1 razabire se kako su te teorije bile daleko od toga da zažive u svim školskim knjigama, pa čak i onima za istu obrazovnu skupinu. Tako još u 1956. godini

Tablica 1 - Prikaz kemijske veze u hrvatskim udžbenicima

Table 1 - Theories of chemical bond in Croatian textbooks

\begin{tabular}{|c|c|c|c|c|c|}
\hline $\begin{array}{l}\text { Godina izdanja } \\
\text { Year of publication }\end{array}$ & $\begin{array}{l}\text { Teorija elektrolitičke } \\
\text { disocijacije } \\
\text { Theory of electrolytic } \\
\text { dissociation }\end{array}$ & $\begin{array}{l}\text { Konstitucijske formule } \\
\text { Constitutional formulas }\end{array}$ & $\begin{array}{l}\text { Lewisove formule } \\
\text { Lewis formulas }\end{array}$ & $\begin{array}{l}\text { Obrazovna razina } \\
\text { Educational level }^{\mathrm{a}}\end{array}$ & $\begin{array}{l}\text { Referencija } \\
\text { Reference }\end{array}$ \\
\hline 1903. & - & + & - & G / G & 53 \\
\hline 1905. & - & - & - & OŠ / MS & 51 \\
\hline 1906. & - & + & - & $\mathrm{G} / \mathrm{G}$ & 52 \\
\hline 1912. & + & + & - & SŠ / HS & 19 \\
\hline 1924. & + & + & - & SŠ / HS & 39 \\
\hline 1940. & + & + & - & SŠ / HS & 28 \\
\hline 1942. & - & + & - & SŠ / HS & 29 \\
\hline 1946. & + & + & - & Sv. / Un. & 30 \\
\hline 1946. & + & + & - & Sv. / Un. & 31 \\
\hline $1946 .{ }^{b}$ & - & + & - & G / G & 40 \\
\hline 1947. & - & - & - & $\mathrm{G} / \mathrm{G}$ & 38 \\
\hline 1947. & + & + & + & G / G & 32 \\
\hline 1947. & + & + & + & Sv. / Un. & 26 \\
\hline 1947. & - & + & - & G / G & 41 \\
\hline 1947. & - & + & - & StŠ / TS & 50 \\
\hline 1949. & + & + & + & Sv. / Un. & 44 \\
\hline 1949. & - & + & - & StŠ / TS & 45 \\
\hline 1951. & + & + & + & Sv. / Un. & 42 \\
\hline 1952. & + & + & - & StŠ / TS & 47 \\
\hline 1953. & + & + & + & $\mathrm{G} / \mathrm{G}$ & 54 \\
\hline 1956. & - & + & - & StŠ / TS & 46 \\
\hline 1956. & - & - & - & SŠ / HS & 55 \\
\hline 1963. & + & + & + & G / G & 43 \\
\hline 1966. & + & + & + & SŠ / HS & 48 \\
\hline 1967. & + & + & + & OŠ / MS & 49 \\
\hline
\end{tabular}

b Godine 1946. započela je školska reforma kojom su četverogodišnje osnovne ("pučke") škole spojene s nižim razredima gimnazije u sedmogodišnje osnovne škole (ref. 37)

${ }^{\mathrm{b}}$ In 1946 started the school reform; elementary, four-year schools were integrated with the lower classes of gymnasium into seven-year "middle" schools (Ref. 37) 
nalazimo srednjoškolske udžbenike u kojima se ne spominju ni ioni ni teorija valencije. Ipak, može se reći da je elektronska teorija kemijske veze postala nedjeljiv dio kako srednjoškolskih tako i osnovnoškolskih udžbenika šezdesetih godina prošloga stoljeća.

Kad se sagleda čitava kronologija, postaje očito da je Arrheniusovoj teoriji trebalo šest desetljeća da posve zaživi u našim srednjim školama, a Lewisovoj teoriji 31 godina da se pojavi u hrvatskim udžbeniku. Sličnu je sudbinu doživio periodni sustav elemenata kojemu je od otkrića, 1869., trebalo 42 godine da nađe mjesto u našem školskom programu. ${ }^{33}$

Ono što je ovdje najzanimljivije je upravo pitanje zašto se Lewisova teorija pojavila u našim udžbenicima tek 1947. Lewis je o njoj napisao knjigu 1923., pa je bilo više nego dovoljno vremena da je Bubanović uvede u prvo izdanje Kemije (1930.). Mislim da neću ići predaleko ako kažem kako je ključna bila upravo pojava Paulingova udžbenika $(1939 .)^{18}$, s kojim su Lewisove formule postale sastavni dio kemijskog kurikuluma. Dakle, novi se kemijski pojmovi pojavljuju u školskim knjigama tek nakon što su ušli u neki vodeći svjetski udžbenik.

I rat je u tome odigrao ulogu. U ratnim prilikama očito nije moglo biti ni govora o unaprjeđenju nastave, pa je s obogaćivanjem kemijskih udžbenika novim sadržajima trebalo pričekati bolja vremena. ${ }^{*} \mathrm{~S}$ druge pak strane u ratu je procvao interes za sve vezano za "atome". Na kraju rata (1945.) bačene su atomske bombe na Hiroshimu i Nagasaki, a potom je uslijedio hladni rat s trkom u nuklearnom naoružanju, u kojem je na svoj način sudjelovala i Jugoslavija sa svojim programom razvoja nuklearnog oružja. ${ }^{34,35}$ Poslijeratne godine u našoj zemlji bile su usto godine intenzivnog industrijskog razvoja i s njime povezane politike forsiranog, posebice tehničkog obrazovanja stanovništva. Svim tim činiteljima treba pripisati pojavu novog pristupa tumačenju kemijske veze u hrvatskim školama.

\section{Literatura \\ References}

1. D. Grdenić, Povijest kemije, Školska knjiga i Novi Liber, Zagreb, 2001., str. 663-728.

2. H. D. Roth, 150 years after their emergence: a new look at Loschmidt's representations of benzene, Bull. Hist. Chem. 38 (1) (2013) 29-36.

3. N. Raos, Što je dvodimenzijska struktura, u N. Raos i H. Peter (ur.), Nove Slike iz kemije, Školska knjiga i Hrvatsko kemijsko društvo, Zagreb, 2004., str. 678-690.

4. N. Raos, A. Miličević, Načini pisanja konstitucijskih formula, Kem. Ind. 61 (9-10) (2012) 435-441.

5. J. Dalton, A New System of Chemical Philosophy, London, 1808.

6. M. Laing, The congress in Karlsruhe, Educ. Chem. 11 (1995) 151-153.

*Boris Kamenar (1929. - 2012.), akademik i profesor kemije na zagrebačkom Prirodoslovno-matematičkom fakultetu, opisao je svoje ratno školovanje u Rijeci: dobio je svjedodžbe četiriju država, počeo učiti pet stranih jezika, a u školskoj godini 1944./45. nastava je trajala samo 45 dana (ref. 36). U ratu je srušeno 17 posto (437) školskih zgrada, a gotovo sve druge bile su teško oštećene (ref. 37).
7. A. M. Butlerov, Einiges über chemische Structure der Körper, Z. Chem. Pharm. 4 (1861) 549.

8. G. V. Bykov, The origin of the theory of chemical structure, J. Chem. Educ. 39 (1962) 220-224, doi: http://dx.doi. org/10.1021/ed039p220.

9. D. L. Larder, F. F. Kluge, Alexander Mikhailovich Butlerov's theory of chemical structure, J. Chem. Educ. 48 (1971) 287291, doi: http://dx.doi.org/10.1021/ed048p287.

10. D. Grdenić, Povijest kemije, Školska knjiga i Novi Liber, Zagreb, 2001., str. 865-887.

11. N. Judaš, O brojenju malih stvari - iliti koliko su mali atomi i molekule, u N. Raos i H. Peter (ur.), Nove Slike iz kemije, Školska knjiga i Hrvatsko kemijsko društvo, Zagreb, 2004., str. 49-62.

12. J. Perrin, Atomi, Državni izdavački zavod Jugoslavije, Beograd, 1946. (J. Perrin, Les Atomes, Rédaction nouvelle, Paris, 1936).

13. N. Raos, Razvoj ideje atomizma, Prirodoslovlje 5 (1) (2005) 45-62.

14. G. N. Lewis, The atom and the molecule, J. Amer. Chem. Soc. 38 (1916) 762-785, doi: http://dx.doi.org/10.1021/ ja02261a002.

15. L. Pauling, G. N. Lewis and the chemical bond, J. Chem. Educ. 61 (1984) 201-203, doi: http://dx.doi.org/10.1021/ ed061p201.

16. G. N. Lewis, Valence and the Structure of Atoms and Molecules, The Chemical Catalog Co., New York, 1923.

17. I. Langmuir, The arrangement of electrons in atoms and molecules, J. Amer. Chem. Soc. 41 (1919) 868-934, doi: http:// dx.doi.org/10.1021/ja02227a002.

18. L. Pauling, The Nature of the Chemical Bond and the Structure of Molecules and Crystals: An Introduction to Modern Structural Chemistry, Cornell University Press, Ithaca, N. Y., 1939.

19. F. Šandor, Anorganska kemija za više razrede srednjih učilišta, Hrvatsko-slavonsko-dalmatinska naklada, Zagreb, 1912.

20. A. Lutkić, Fran Bubanović (Sisak, 1883. - Zagreb, 1955.), Prirodoslovlje 7 (1-2) (2007) 33-46.

21. F. Bubanović, Iz moderne kemije, Matica hrvatska, Zagreb, 1929

22. F. Bubanović, Slike iz kemije, Matica hrvatska, Zagreb, 1917.

23. N. Raos, Bubanović i Arrheinus, Kem. Ind. 54 (6) (2005) 320-322.

24. N. Raos, Letters of Svante Arrhenius to his former Croatian student, Bull. Hist. Chem. 33 (1) (2008) 12-16.

25. F. Bubanović, Kemija za slušače kemije, medicine i farmacije, Knjiga prva. I. Teorijski ili opći dio, II. Anorganska kemija, Naklada "Farmaceutskog vjesnika", Zagreb, 1930.

26. F. Bubanović, Kemija za slušače kemije, medicine i farmacije, Treće, popravljeno i dopunjeno izdanje. Knjiga prva: Anorganska kemija. Svezak prvi: Opći dio anorganske kemije. Nakladni zavod Hrvatske, Zagreb, 1947.

27. F. Bubanović, Kemija za slušače kemije, medicine i farmacije, Knjiga druga. I. organska kemija, II. Biokemija, Naklada "Farmaceutskog vjesnika", Zagreb, 1931.

28. Z. Pinterović, Kemija za više razrede srednjih i sličnih škola, Naklada školskih knjiga i tiskanica Banovine Hrvatske, Zagreb, 1940 .

29. Z. Pinterović, Kemija za niže razrede srednjih škola, Drugo izdanje, Nakladni odjel Hrvatske državne tiskare, Zagreb, 1942.

30. F. Bubanović, Praktikum medicinske kemije, Svezak prvi: Anorganski i organski dio, Treće izdanje, Naklada knjižare "Juraj Križanić", Zagreb, 1946.

31. M. Ferić, Uvod u studij kemije, II. prošireno izdanje, Hrvatsko ljekarničko društvo u Zagrebu, Zagreb, 1946. 
32. V. N. Verhovski, Anorganska kemija za VII. razred gimnazije, Nakladni zavod Hrvatske, Zagreb, 1947. (В. Н. Верховский, Неорганическая химия, Moskva 1944. - 1945.)

33. N. Raos, Periodni sustav u Hrvata, Kem. Ind. 60 (12) (2011) 633-638.

34. V. Pravdić, Nuklearni program Jugoslavije 1950-ih i 1960-ih godina. Sjećanja iz žablje perspektive, Encyclopaedia Moderna 15 (1) (1995) 31-39.

35. S. Kaučić, Zagrebački ciklotron, monografija, Institut "Ruđer Bošković", Zagreb, 2006.

36. B. Kamenar, Sjećanja jednog kemičara, HDKI/Kemija u industriji, Zagreb, 2011., str. 7.

37. Hrvatska, u Enciklopedija Jugoslavije, sv. 4, Leksikografski zavod FNRJ, Zagreb, 1955, str. 174-176.

38. V. N. Verhovski, Anorganska kemija za VI. razred gimnazije, Nakladni zavod Hrvatske, Zagreb, 1947. (В. Н. Верховский, Неорганическая химия, Moskva, 1944. - 1945.)

39. M. Vladen, Anorganska kemija i kemijska tehnologija za trgovačke akademije, više trgovačke škole i ine srednje strukovne zavode, Bibliografski zavod d. d., Nakladna knjižara, Zagreb, 1924.

40. M. Krajčinović, Kemija za IV. razred gimnazije, Nakladni zavod Hrvatske, Zagreb, 1946.

41. M. Krajčinović, V. Hahn, Organska kemija za VIII. razred gimnazije, Nakladni zavod Hrvatske, Zagreb, 1947.

42. T. Pinter, Fizikalna kemija za medicinare, Školska knjiga, Zagreb, 1951.

43. J. Herak, M. Herak, M. Herak, Fizikalna kemije za gimnazije prirodoslovno-matematičkog i pedagoškog smjera, Školska knjiga, Zagreb, 1963.

44. A. Režek, Organska kemija za medicinare, Nakladni zavod
Hrvatske, Zagreb, 1949.

45. M. Milić, Kemija za škole učenika u privredi i industrijske škole, Vjesnik rada, Beograd, 1949.

46. P. Krivačić, Kemija za škole učenika u privredi, Školska knjiga, Zagreb, 1956.

47. M. Vladen, Tehnologija s poznavanjem robe i kemijom. Udžbenik za ekonomske tehnikume, I. dio, Školska knjiga, Zagreb, 1952.

48. V. Karas-Gašparec, Z. Gašparec, Opća, anorganska i organska kemija sa biokemijom. Udžbenik za škole za medicinske sestre, Medicinska knjiga, Beograd i Zagreb, 1966.

49. L. Ivanček, Kemija za osnovno obrazovanje odraslih, Školska knjiga, Zagreb, 1967.

50. M. Vladen, Kemija i kemijska tehnologija. I. dio: Anorganska kemija. Udžbenik za tehničke škole i ekonomske tehnikume, Nakladni zavod Hrvatske, Zagreb, 1947.

51. A. Korlević, J. Beyer, Počela kemije i mineralogije za niže razrede srednjih učilišta, ženski licej, više djevojačke škole i više pučke škole realnog smjera, II. prerađeno izdanje, Hrvatsko-slavonsko-dalmatinska zemaljska vlada, Zagreb, 1905.

52. J. Domac, Organska kemija ili kemija ugljikovih spojeva za više razrede realnih gimnazija i realaka, III. izdanje, Hrvatsko-slavonsko-dalmatinska zemaljska vlada, Zagreb, 1906.

53. N. Hofmann, Kemija i mineralogija za četvrti razred realnih gimnazija i realaka, prvo hrvatsko izdanje po drugom češkom izdanju, preveo F. Šandor, Hrvatsko-slavonsko-dalmatinska zemaljska vlada, Zagreb, 1903.

54. E. Matijević, M. Kesler, Kemija za VII. razred gimnazije, Školska knjiga, Zagreb, 1953.

55. J. Herak, Opča i anorganska kemija za više razrede srednjih škola, I. dio, Školska knjiga, Zagreb, 1956. 


\section{SUMMARY \\ Theories of the Chemical Bond in Croatian Textbooks \\ Nenad Raos}

There are two basic theories of chemical constitution; the first starts from stoichiometry ("chemical structure"), and the second from the structure of the atom ("physical structure"). In Croatian textbooks, constitution and valence of the elements were not interpreted "physically" until 1947, when the first university and the first high-school textbook with electronic Lewis formulas appeared. The late appearance of "physical structure" in Croatian textbooks - 31 years after Lewis's first paper on the chemical bond (1916) and 14 years after the publication of his book "Valence and the Structure of Atoms and Molecules" (1923), could be explained by the hypothesis that Croatian authors were not inspired by Lewis's work, but rather with Pauling's textbook "The Nature of the Chemical Bond" (1939). The second factor was World War II in Croatia (1941-1945), which delayed innovations in the teaching of chemistry.

\section{Keywords}

History of chemistry, teaching of chemistry, structural formulas, constitution of molecules

Institute for Medical Research and

Occupational Health

Ksaverska c. 2, P.O.B. 291, 10001 Zagreb,

Original scientific paper

Croatia

Received February 26, 2015

Accepted April 9, 2015 